\title{
Transcriptomic Analysis, Motility and Biofilm Formation Characteristics of Salmonella typhimurium Exposed to Benzyl Isothiocyanate Treatment
}

\author{
Tong-Xin Niu ${ }^{1}$, Xiao-Ning Wang ${ }^{1}$, Hong-Yan $\mathrm{Wu}^{2}{ }^{2}$, Jing-Ran $\mathrm{Bi}^{1}{ }^{1}$, Hong-Shun Hao ${ }^{3}$, \\ Hong-Man Hou ${ }^{1}$ and Gong-Liang Zhang ${ }^{1, *}$ \\ 1 School of Food Science and Technology, Dalian Polytechnic University, Dalian 116034, China; \\ ntx156560120@gmail.com (T.-X.N.); wxn1531972535@gmail.com (X.-N.W.); \\ bijingran1225@foxmail.com (J.-R.B.); houhongman2011@hotmail.com (H.-M.H.) \\ 2 Graduate School of Environmental and Life Science, Okayama University, Okayama 700-8530, Japan; \\ wuhongyan1908@hotmail.com \\ 3 Department of Inorganic Nonmetallic Materials Engineering, Dalian Polytechnic University, Dalian 116034, \\ China; haohs@dlpu.edu.cn \\ * Correspondence: zhangg178@gmail.com; Tel.: +86-411-8632-2020
}

Received: 19 December 2019; Accepted: 1 February 2020; Published: 4 February 2020

\begin{abstract}
Salmonella typhimurium (S. typhimurium) is a common foodborne pathogen that not only causes diseases and contaminates food, but also causes considerable economic losses. Therefore, it is necessary to find effective and feasible methods to control S. typhimurium. In this study, changes in S. typhimurium after treatment with benzyl isothiocyanate (BITC) were detected by transcriptomics to explore the antibacterial effect of BITC at subinhibitory concentration. The results showed that, in contrast to the control group (SC), the BITC-treated group (SQ_BITC) had 197 differentially expressed genes (DEGs), of which 115 were downregulated and 82 were upregulated. We screened out eight significantly downregulated virulence-related genes and verified gene expression by quantitative Real-time Polymerase Chain Reaction (qRT-PCR). We also selected motility and biofilm formation to observe the effects of BITC on the other virulence related factors of S. typhimurium. The results showed that both swimming and swarming were significantly inhibited. BITC also had a significant inhibitory effect on biofilm formation, and showed an effect on bacterial morphology. These results will be helpful for understanding the mechanism of the antibacterial action of BITC against $S$. typhimurium and other foodborne pathogens.
\end{abstract}

Keywords: Salmonella typhimurium; benzyl isothiocyanate; transcriptome; motility; biofilm

\section{Introduction}

In recent years, with increasing numbers of new foodborne diseases caused by microbial contamination, consumers and the food industry have begun to focus on food safety [1]. Salmonella typhimurium (S. typhimurium) is a common, gram-negative, food-borne bacterium with flagella [2]. It is widely found in poultry, animal husbandry, and many kinds of foods and animal feed all over the world and has an extremely important economic impact on food safety and health [3]. According to the previous research, when $S$. typhimurium causes fatal infections in mice, multiple virulence genes are required, and the pathogenicity of the bacteria is closely related to its locomotion and membrane formation abilities. The components of the outer membrane (proteins and lipopolysaccharides) as well as the pili and flagella, play important roles in the colonization and systemic infection in animal and human hosts of S. typhimurium [4,5]. Once attached to an abiotic surface, planktonic bacterial cells gather in hydrated extracellular aggregates to synthesis the proteins, polysaccharides, and nucleic acids 
to form biofilms [6]. Biofilms protect bacteria in a growth pattern that allows them to survive harsh environments [7], and bacteria that produce biofilms are more resistant to antibiotics. Study of the motility and biofilm formation of $S$. typhimurium helps researchers to efficiently design and optimize the beneficial properties of various mechanisms of new anti-infective drugs [8]. S. typhimurium infections are so deadly that more than a million people are treated each year in the United States alone. In consequence, the economic impact of $S$. typhimurium infection on food safety and health has been a driving force in the development of new antimicrobial agents [9].

In the past, people have tried to solve this problem using synthetic chemical preservatives. However, the adverse effects on humans from the overuse of chemical preservatives have far exceeded those of the pathogenic microorganisms themselves [10]. Therefore, we urgently need to replace synthetic preservatives with natural antimicrobials. Benzyl isothiocyanate (BITC) which is extensively found in senvy, pilu oil, cruciferous plants and papaya seeds [11], has been shown to exert potential health benefits to humans. According to the recent studies, BITC shows excellent therapeutic effects on cancer by reversing or blocking the proliferation of DNA-damaged precancerous cells [12-14]. In addition, BITC antibacterial mechanisms in foodborne bacteria have been widely studied. For example, the biofilm integrity, bacterial morphology, membrane potential, ATP, and membrane hydrophilicity of bacteria treated with BITC have been investigated [15-17]. However, the mechanism of antibacterial activity of BITC on S. typhimurium is still unclear, and further studies are needs.

In the last decade of rapid technological development, transcriptome technology has become an essential tool in the biological sciences [18,19]. Transcriptomic analysis is widely used because it can comprehensively evaluate differential genes and enrichment pathways in samples. The transcriptomics has been applied to comprehensively analyze S. typhimurium for exploring bacteriostatic mechanisms [20,21]. For example, the effects of cranberry extract and antimicrobial proteins on the growth rates and transcriptomics of $S$. typhimurium were investigated. The expressions of related genes, such as those involved in iron acquisition, flagella, energy metabolism, pathogenicity, virulence islands and the cell membrane, were significantly downregulated after bacteriostatic treatment in S. typhimurium [22,23]. According to Song et al. and Wang et al. [24,25], the transcriptome was used to explore the mechanism of antibacterial activity of BITC on Vibrio parahaemolyticus and Staphylococcus aureus. It was shown and proved that BITC had a good bacteriostasis effect on these two food-borne pathogens. However, studies on the mechanism of BITC action on S. typhimurium by transcriptome detection have not been reported.

Therefore, to study the mechanism of BITC action on S. typhimurium, we conducted an in-depth analysis at the transcriptome level. In order to investigate the bacteriostatic mechanism of BITC, the differential expressed genes related to virulence were screened out through the transcriptome results. The expression of genes was further verified by quantitative Real-time Polymerase Chain Reaction (qRT-PCR). Additionally, the effects of BITC on the motility and biofilm formation of S. typhimurium were studied, and the mechanism of BITC action on S. typhimurium was discussed from the molecular and phenotypic levels.

\section{Results}

\subsection{Antibacterial Tests}

According to the minimal inhibitory concentration (MIC) determined by microbroth dilution, the MIC of BITC for S. typhimurium is $250 \mu \mathrm{mol} / \mathrm{L}$. According to the results of the antibacterial test, the subinhibitory concentration of BITC in the subsequent experiments was determined.

\subsection{Global Changes at the Transcriptome Level}

To analyze the effects of BITC on S. typhimurium, 1/4 MIC $(62.5 \mu \mathrm{mol} / \mathrm{L})$ was selected as subinhibitory concentration for the following studies. The transcriptome sequencing was performed on the RNA of 
the control group (SC) and the 1/4 MIC BITC-treated group (SQ_BITC). The product was purified by PCR amplification. Finally, six cDNA libraries were built. Each of the libraries was sequenced using Illumina HiSeqTM 2500/MiSeqTM. We acquired a total of $16.44 \mathrm{~Gb}$ of data, including 112,664,390 raw reads and 109,599,530 clean reads. The six cDNA libraries for SC and SQ_BITC samples generated $24,399,752,21,013,012,14,444,786,17,951,308,15,258,326$, and 19,597,206 clean reads. An overview of the transcriptome assembly statistics is shown in Table 1 . The error rate of single base location sequencing in all six groups was less than $1 \%$. The Q20 and Q30 percentages were equal to or higher than $98 \%$ and $94 \%$, respectively. The downstream analyses were based on good quality data of Q20 and Q30.

Table 1. Summary of RNA-seq alignment.

\begin{tabular}{cccccccc}
\hline Sample Name & Raw Reads & Clean Reads & Clean Bases $(\mathbf{G b})$ & Error (\%) & Q20 (\%) & Q30 (\%) & GC (\%) \\
\hline SC1 & 24399752 & 23567734 & 3.54 & 0.02 & 98.46 & 95.16 & 53.1 \\
SC2 & 21013012 & 20367416 & 3.06 & 0.02 & 98.24 & 94.74 & 52.6 \\
SC3 & 14444786 & 14083514 & 2.11 & 0.02 & 98.28 & 94.78 & 52.89 \\
SQ_BITC1 & 17951308 & 17535420 & 2.63 & 0.03 & 98.00 & 94.15 & 52.95 \\
SQ_BITC2 & 15258326 & 14882480 & 2.23 & 0.02 & 98.12 & 94.46 & 54.02 \\
SQ_BITC3 & 19597206 & 19162966 & 2.87 & 0.02 & 98.19 & 94.62 & 52.94 \\
\hline
\end{tabular}

Q20: percentage of bases with a Phred value $>20$; Q30: percentage of bases with a Phred value $>30$.

\subsection{Analysis of Differentially Expressed Genes (DEGs)}

RNA sequencing technology was used to analyze SC and SQ_BITC samples to study the inhibitory mechanism of BITC on S. typhimurium. The analysis of DEGs was divided into three parts: volcanic maps, gene ontology (GO) analysis and Kyoto encyclopedia of genes and genomes (KEGG) signaling pathway enrichment analysis. Volcanic maps were used to show the overall distribution of the differentially expressed genes in the SQ_BITC and SC groups. The selection criteria were $P<0.05$. A total of 197 important DEGs were identified in the experimental group. There were 115 downregulated genes and 82 upregulated genes (Figure 1).

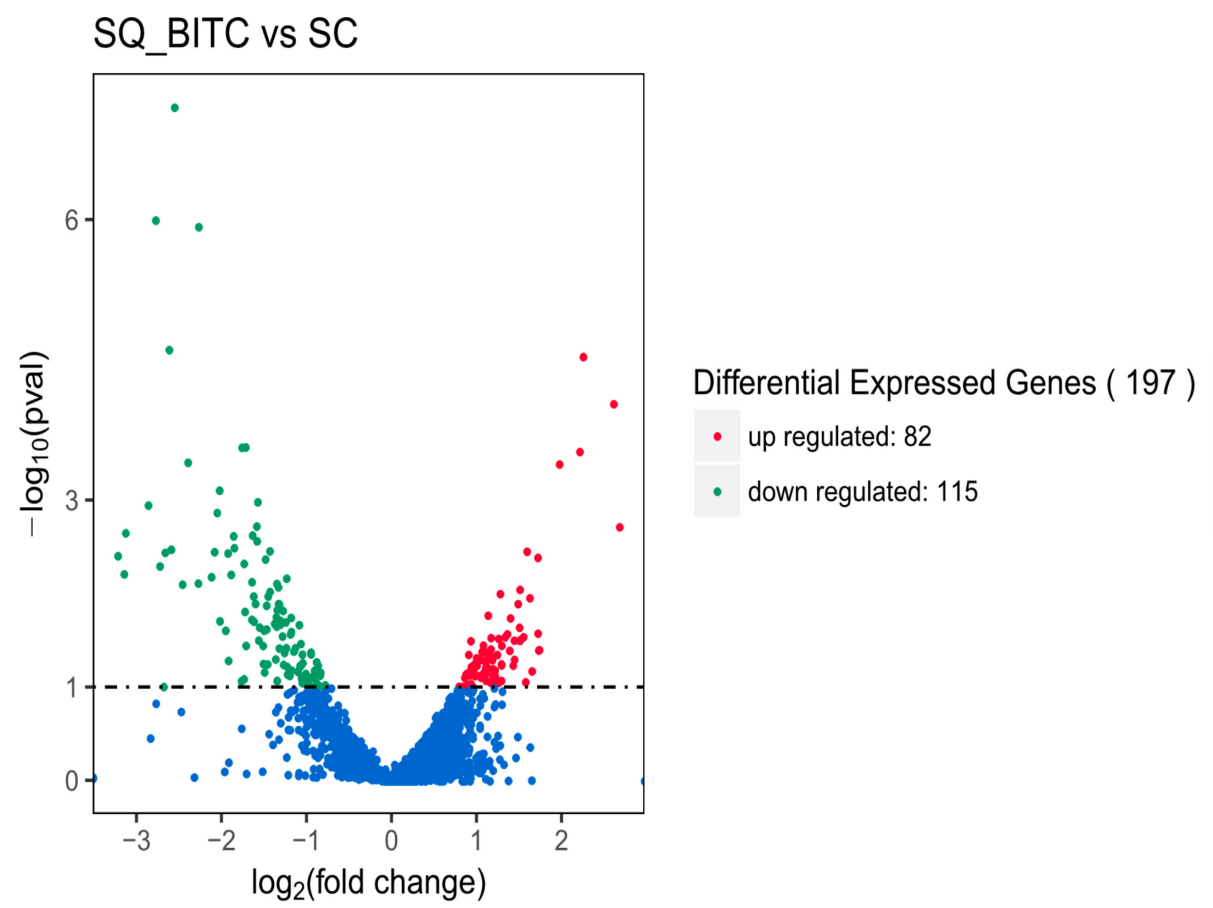

Figure 1. Volcano map of differentially expressed genes (DEGs) for SQ_BITC vs SC. Different colors (red, green, and blue) represent upregulated, downregulated, and no significant changes, respectively, in DEGs between the SQ_BITC and SC groups. 
Gene ontology is a classification system that includes molecular functions, biological processes and cell components. As shown in Figure 2, the distribution of differential genes in GO was used to explore the differences in physiological and metabolic functions and biological processes between the experimental group (SQ_BITC) and the control group (SC). According to transcriptomic data, 197 genes were annotated into different GO terms. The $30 \mathrm{GO}$ terms with the most significant enrichment were selected and included 20 biological processes and 10 molecular functions.

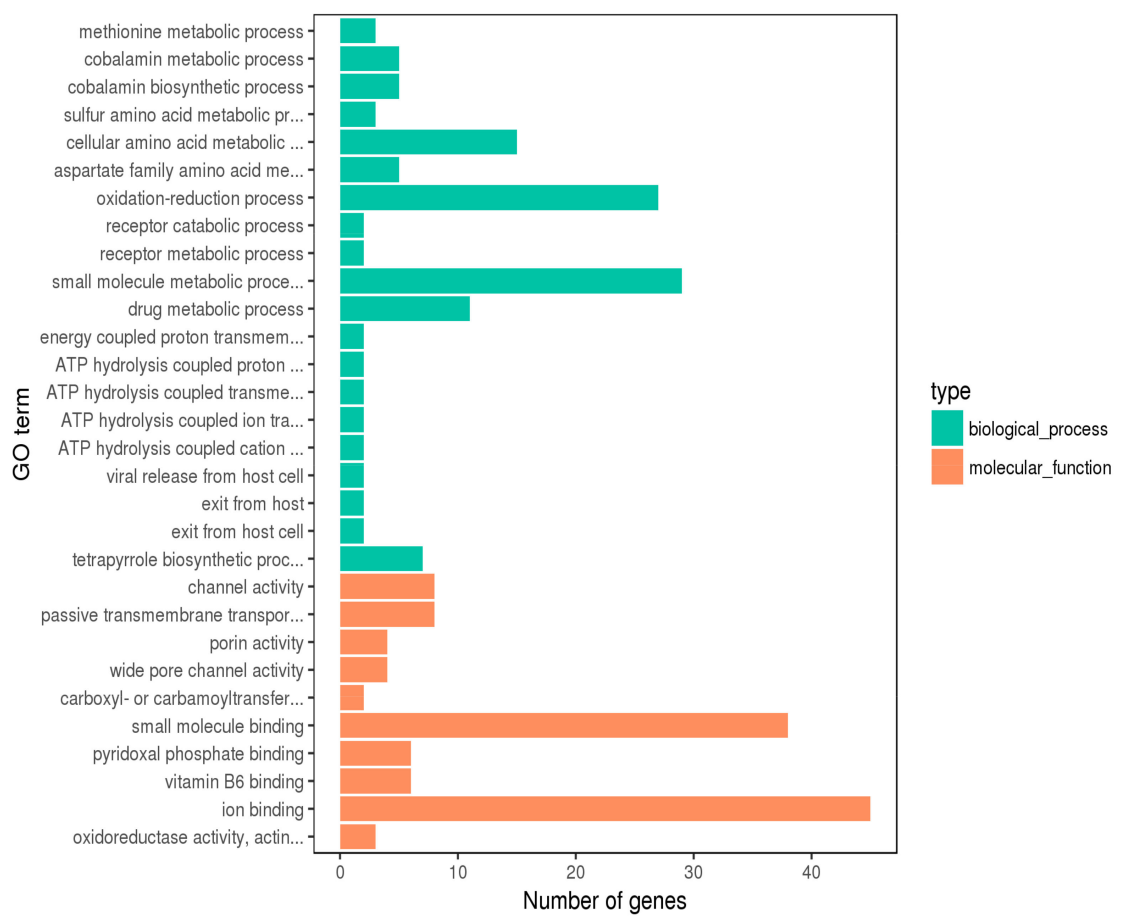

Figure 2. Gene ontology (GO) analysis of differentially expressed genes (DEGs) for SQ_BITC vs SC.

The 30 GO terms with the most significant enrichment were shown.

Each biological function is completed through the cooperation of different genes. The most important biochemical or signaling pathways in which differentially expressed genes participate are determined by the significant enrichment of the pathway. Following GO analysis of the differential genes, KEGG signaling pathway enrichment analysis was performed. Compared with the control group, 197 differentially expressed genes were enriched for 61 pathways after the addition of 1/4 MIC BITC in the experimental group; the 20 most abundant pathways were selected, as shown in Figure 3. Arginine biosynthesis, oxidative phosphorylation, citrate cycle (TCA cycle), Salmonella infection and amino sugar and nucleotide sugar metabolism pathways were the most significantly enriched.

\subsection{Expression of Virulence-Related Genes by qRT-PCR}

For gene expression, qRT-PCR is a powerful tool and the most commonly used method to confirm transcriptomic data and analyze genes. By screening out genes related to virulence through the transcriptome results, qRT-PCR can directly reflect the influence of BITC on the expression of its pathogenicity correlation genes, further verify the transcriptomic results. From the RNA sequencing data, virulence-related genes with significantly reduced expression were selected according to the transcriptomic results, including ssaT, STY2983, pagC, yscR, sseB, sifB, ssaH, and sseD, as shown in Table 2. The validation results of DEGs were consistent with the results of the RNA-seq analysis, indicating that RNA-seq successfully identified DEGs. Additionally, it was verified that, the expression of virulence-related genes decreased significantly in S. typhimurium by BITC treatment. The results are shown in Figure 4. 


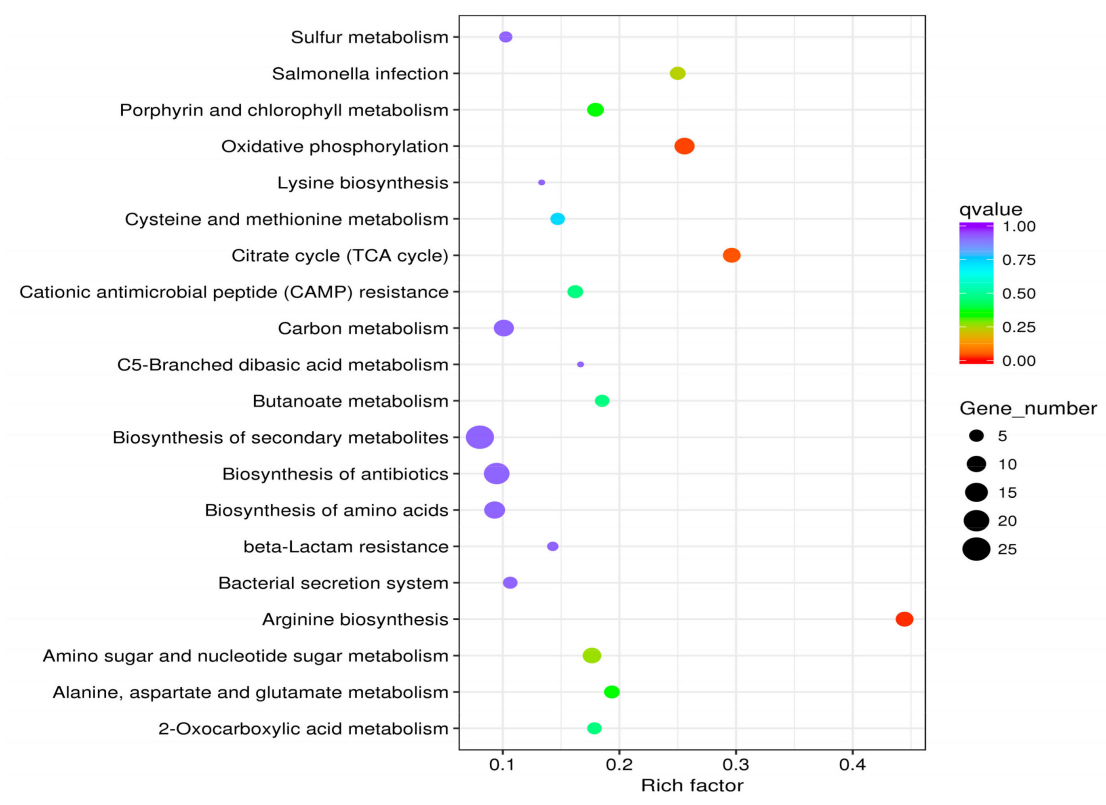

Figure 3. The most abundant pathways for a total of 197 differentially expressed genes. The size of the dot is proportional to the number of genes; the closer the $q$ value is to 0 , the greater the extent of enrichment.

Table 2. Data for the differentially expressed genes.

\begin{tabular}{cccccc}
\hline Gene_ID & Gene Name & $\begin{array}{c}\mathbf{l o g}^{2} \text { FoldChange } \\
\text { (SQ_BITC vs. SC) }\end{array}$ & $\begin{array}{c}\text { Pval } \\
\text { (SQ_BITC vs. SC) }\end{array}$ & $\begin{array}{c}\text { Padj } \\
\text { (SQ_BITC vs. SC) }\end{array}$ & $\begin{array}{c}\text { Significant } \\
\text { (SQ_BITC vs. SC) }\end{array}$ \\
\hline 1248073 & $s s a T$ & -1.5829 & 0.0026999 & 0.48096 & DOWN \\
1249210 & $S T Y 2897$ & -1.4314 & 0.0034612 & 0.48693 & DOWN \\
1248241 & pagC & -1.234 & 0.006776 & 0.68515 & DOWN \\
1248075 & $y s c R$ & -1.4305 & 0.009399 & 0.7991 & DOWN \\
1248096 & $s s e B$ & -1.2767 & 0.014982 & 1 & DOWN \\
1247852 & $s i f B$ & -1.356 & 0.01751 & 1 & DOWN \\
1248087 & $s s a H$ & -1.3073 & 0.020987 & 1 & DOWN \\
1248093 & $s s e D$ & -1.3507 & 0.022094 & 1 & DOWN \\
\hline
\end{tabular}

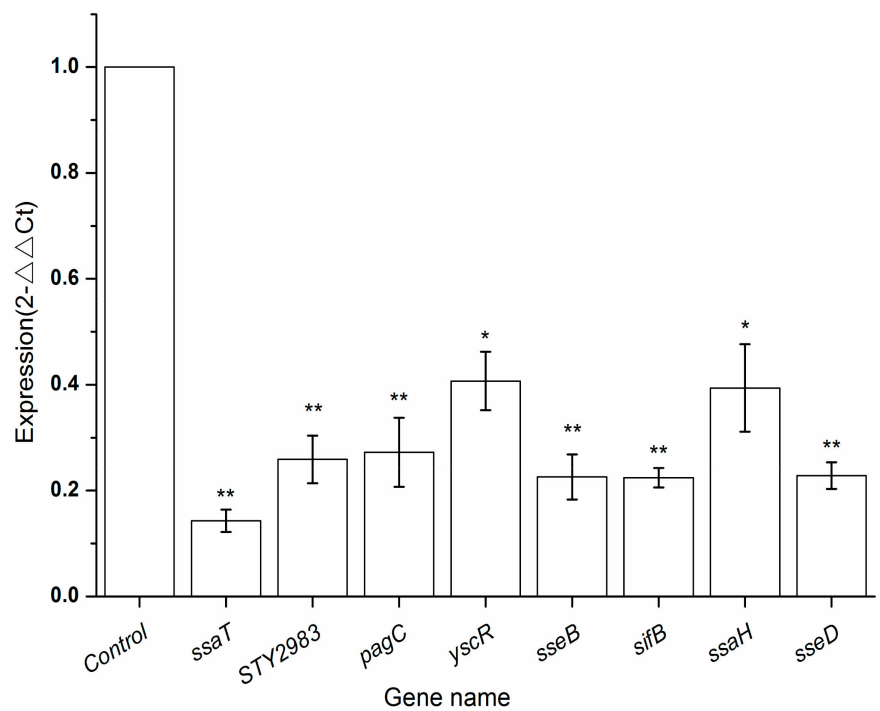

Figure 4. qRT-PCR validation of differentially expressed genes (DEGs). The relative expressions of $s s a T, S T Y 2983, p a g C, y s c R, s s e B, s i f B, s s a H$ and $s s e D$ were compared with $16 S r R N A$ in the control group. The bars are expressed as the means \pm SD from three independent replicates. ${ }^{* \prime}$ indicates significant differences $(p<0.05)$. ${ }^{* * \prime}$ indicates extremely significant differences $(p<0.01)$. 


\subsection{Motility of S. typhimurium Induced by BITC}

The motility of bacteria is related to the presence of flagella, which is closely related to the pathogenicity of bacteria. By observing the motility of S. typhimurium, we expected to explore the effect of BITC on the movement of $S$. typhimurium and its flagella. The results are shown in Figure 5. With the increase in BITC concentration, the motility diameter of $S$. typhimurium on the plate decreased significantly, and the inhibitory effect gradually increased. The results showed that BITC could significantly inhibit the motility of $S$. typhimurium in a concentration-dependent manner.
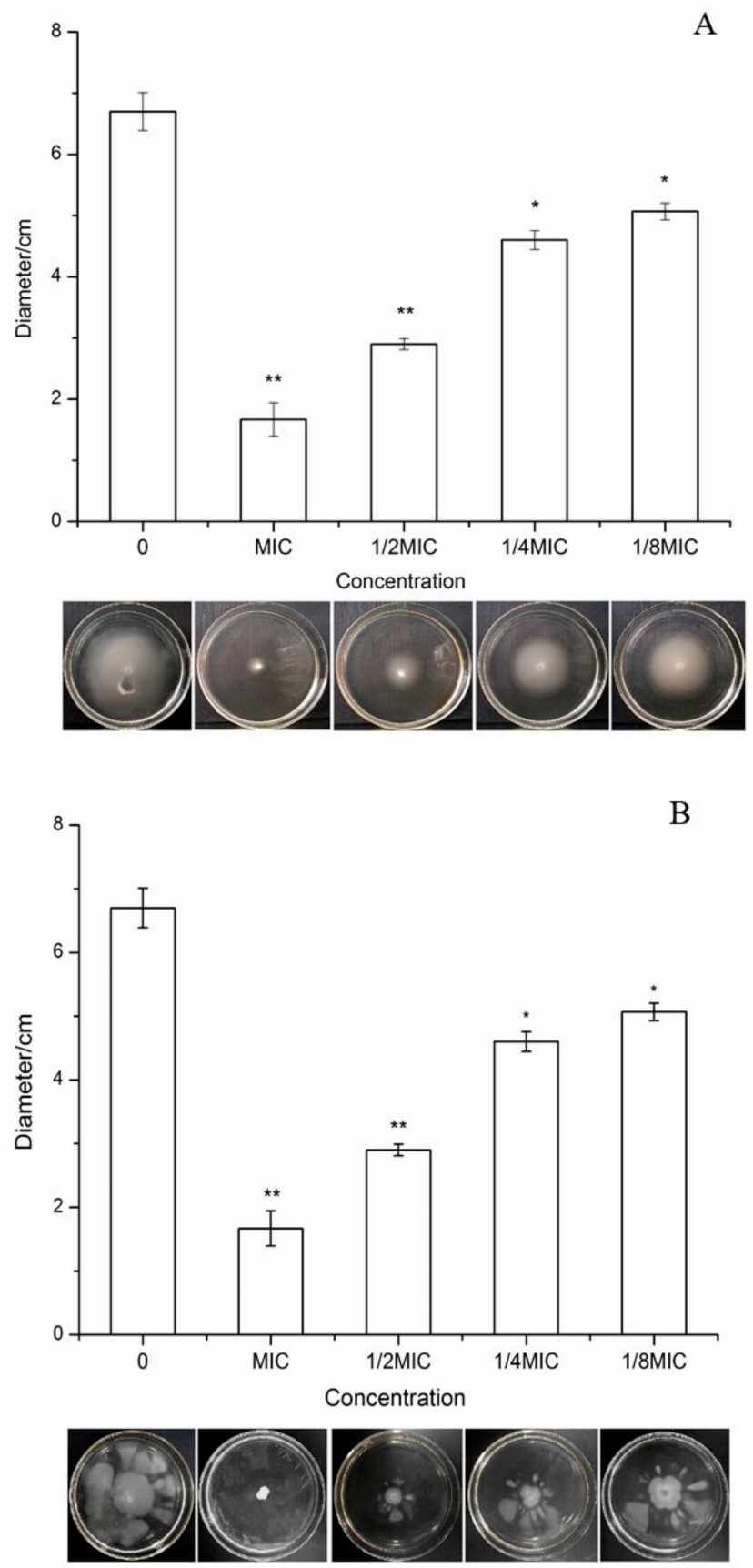

Figure 5. Inhibitory effects of BITC at different concentrations on the motility of S. typhimurium. The bacteria were treated with BITC at different concentrations (MIC, 1/2MIC, 1/4MIC and 1/8MIC) at $37^{\circ} \mathrm{C}$ for $12 \mathrm{~h}(\mathbf{A})$ and $48 \mathrm{~h}(\mathbf{B})$, respectively, and the diameters were observed and measured. Figure A indicated the results of swimming and Figure B indicated the results of swarming. ' $*$ ' indicates significant differences $(p<0.05) .{ }^{، * * \prime}$ indicates extremely significant differences $(p<0.01)$. 


\subsection{Effects of BITC on Biofilm Formation of S. typhimurium}

There is a close relationship between biofilm formation and bacterial pathogenicity. We can explore and speculate the mechanism of natural bacteriostatic agents by investigating the changes of biofilm formation characteristics in foodborne pathogens. The effect of BITC on biofilm formation of S. typhimurium was observed by using scanning electron microscopy. As shown in Figure $6 \mathrm{~A}, \mathrm{~B}$, in the control groups (without BITC treatment), more biofilm was detected adhering to the slides. However, compared to the control group, the samples treated with 1/8 MIC and 1/4 MIC BITC showed significant decreases in the adhesion rate that was, dependent on concentration (Figure 6C-F). In addition, damaged bacteria (shrinkage, corrugation, and rupture) were present on the slides treated with BITC at concentration of 1/4 MIC (Figure 6D), while no damaged bacteria were present on the slides in the control group (Figure 6B). Therefore, it indicated that BITC had a significant inhibitory effect on the biofilm formation of S. typhimurium.
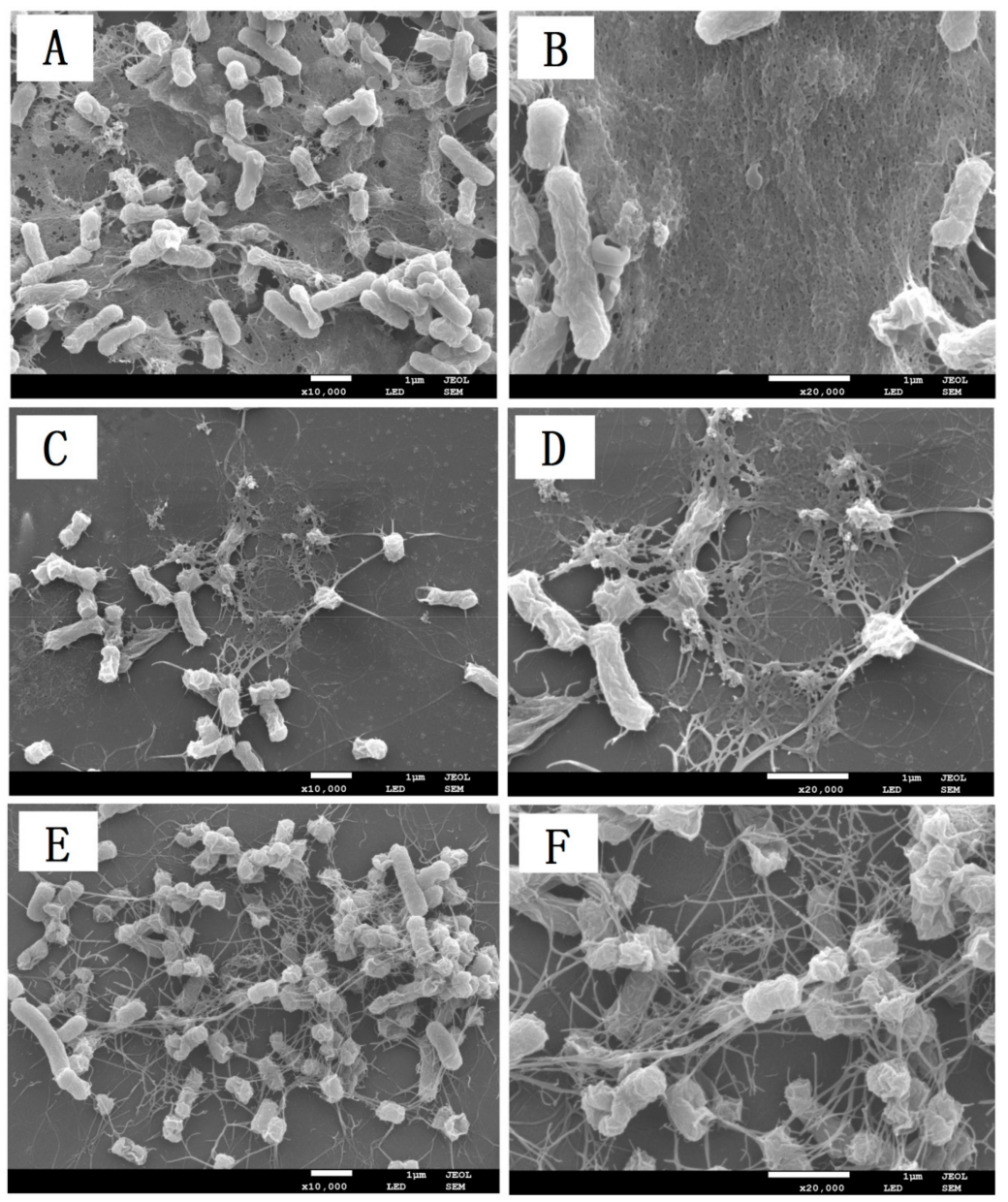

Figure 6. Effects of BITC on biofilm formation of $S$. typhimurium at different concentrations. S. typhimurium was added with BITC at $1 / 4 \mathrm{MIC}(\mathbf{C}, \mathbf{D})$ or $1 / 8 \mathrm{MIC}(\mathbf{E}, \mathbf{F})$ in 6-well plates and cultured for $36 \mathrm{~h}$. MH instead of BITC was used as negative control (A,B). The samples were observed under SEM, and the images were collected at $10000 \times(\mathbf{A}, \mathbf{C}, \mathbf{E})$ and $2000 \times(\mathbf{B}, \mathbf{D}, \mathbf{F})$ magnifications.

\section{Discussion}

As a common foodborne bacterium, S. typhimurium has an important impact on food safety and human health. Therefore, the study of natural bacteriostatic agents for S. typhimurium has never stopped. For example, according to Wafa et al., anthocyanin from pomegranate peel extract had good antibacterial activity against $S$. typhimurium, and the MIC was $10.75-12.5 \mathrm{mg} / \mathrm{mL}$ [26]. Dihydromyricetin from momordica, as a new bacteriostatic agent, had a significant effect on the oxidative respiration 
metabolism and membrane integrity of S. typhimurium with MIC of $0.625 \mathrm{mg} / \mathrm{ml}$ [27]. Compared with the other natural extracts, BITC has a more significant antibacterial effect on S. typhimurium, and the MIC is only $250 \mu \mathrm{mol} / \mathrm{L}$. This highlights that BITC is a good natural product for inhibiting S. typhimurium. Moreover, it has been proven by a large number of experimental studies that the antibacterial effect of BITC against foodborne pathogens is of great significance for food safety and clinical research [12,28-30].

With the development of genome technologies, the study of $S$. typhimurium by transcriptome analysis is increasing. Das et al. studied transcriptome changes of $S$. typhimurium after treatment with cranberry extract and found that the expression of several pathogenicity-related genes, including ssaT on virulence island II, were significantly downregulated [22]. SPI2, which encodes T3SS2, plays an important role in the survival and pathogenicity of S. typhimurium in host cells [31-33]. As shown in Figure 4, after BITC treatment, the expression levels of virulence-related genes in S. typhimurium SPI2, including $s s a T$, ssaH, sseB, sseD, pagC, yscR, and sifB, were significantly decreased. These results are consistent with the previous studies [34,35]. Furthermore, transcriptome technology has also been used to explore the antibacterial mechanism of BITC against Vibrio parahaemolyticus and Staphylococcus aureus. The results showed that after BITC treatment, the virulence related genes were significantly down regulated, such as thd, fliA, fliG, and fliI of Vibrio parahaemolyticus; nuc, spa, cp8F of Staphylococcus aureus [24,25]. Hence, the application of transcriptome analysis can be significant for exploring bacteriostatic mechanisms.

A large number of studies have demonstrated that the motility of bacteria is related to flagella, which are closely related to the pathogenicity of bacteria; thus, research on the influence of bacteriostatic agents on the motility of bacteria is also extensive [36]. According to Lou et al., eugenol and its nanoemulsion both had a significant effect on the swarming motility and biofilm formation of foodborne bacteria [37]. Pomegranate peel extract has also been shown to have a strong effect on S. typhimurium motility [38]. In Figure 5, it is obvious that the swimming and swarming abilities of S. typhimurium after BITC treatment were significantly reduced. When the concentration was equal to the MIC, the motility of S. typhimurium was completely inhibited. Jitendra et al. [28] have indicated that $125 \mu \mathrm{g} / \mathrm{mL}$ BITC for S. typhimurium and $150 \mu \mathrm{g} / \mathrm{mL}$ BITC for E. coli O157:H7 can significantly inhibit the motility of both bacteria. Selwan et al., and Smriti et al., $[39,40]$ have shown that the motility regulated by flagella is significantly different when the expression of flagella system-related genes is changed. Therefore, we inferred from the transcriptome that the changes in S. typhimurium motility after BITC treatment may be due to the downregulation of $y s c R$ gene expression, but further verification is still needed.

Based on previous studies, biofilms are closely related to the pathogenicity of pathogenic bacteria $[8,9]$. BITC as main active compound in plant extracts had a significant inhibitory effect on the biofilm formation in bacteria, such as Escherichia coli O157:H7 [41] and Streptococcus mutans [42]. In Figure 6, it is obvious that, after being treated with BITC, the adhesion of the biofilm was significantly reduced, and S. typhimurium was wrinkled and deformed at 1/4 MIC concentration. This conclusion is consistent with the results of Borges et al., and Saleh et al., showing that BITC significantly inhibits S. typhimurium growth and changes the integrity of biofilms $[15,17]$. These results indicate that BITC has significant influence on the biofilm formation characteristics of S. typhimurium. In our preliminary studies, we found that the relative electrolysis leakage and extracellular ATP content of S. typhimurium increased to varying degrees, while the membrane potential decreased after BITC treatment (data not shown). This suggests that the BITC may cause the cell membrane damage of S. typhimurium, and we inferred that the mechanism of BITC on S. typhimurium may be related to biofilm as well as cell membrane.

\section{Materials and Methods}

\subsection{Bacterial Strain and Activation}

Salmonella Typhimurium ATCC14028 was obtained from China microbial culture preservation center. The frozen S. typhimurium stock was inoculated on beef extract peptone medium and cultured 
at $37^{\circ} \mathrm{C}$ for $12 \mathrm{~h}$. Then, $100 \mu \mathrm{L}$ of bacterial suspension was transferred to $10 \mathrm{~mL}$ of the same liquid medium and cultured to a stable growth stage. $1 \mathrm{~mL}$ of $S$. typhimurium bacterial suspension was inoculated to $100 \mathrm{~mL}$ beef extract liquid medium, simultaneously, BITC was added at subinhibitory concentrations. Bacterial suspension without BITC was used as negative control. After culture for $12 \mathrm{~h}$ at $37^{\circ} \mathrm{C}$, bacterial suspension was centrifuged at $8000 \mathrm{rpm}$ for $10 \mathrm{~min}$ at $4{ }^{\circ} \mathrm{C}$. The thallus precipitate was used for further studies.

\subsection{Antimicrobial Tests}

The minimum inhibitory concentration (MIC) was determined by broth microdilution. After the dilution of BITC at different multiples, it was added to a sterile 96-hole microporous plate together with the bacterial culture solution for $12 \mathrm{~h}$ at $37^{\circ} \mathrm{C}$. The control group was MHB with or without bacterial culture.

\subsection{RNA Extraction}

After treatment with 1/4 MIC BITC, S. typhimurium was cultured to a stable growth stage, which was followed by total RNA extraction using RNAprep Pure Cell/Bacterial Kit (Tiangen Biotech, Beijing, China). Total RNA concentration was determined by measuring OD260 nm/OD $280 \mathrm{~nm}$ ratio. Agarose gel electrophoresis and a UV transilluminator (Versa Doc, Shanghai, China) were used to examine whether the RNA had been contaminated or degraded. The RNA samples were stored at $-80^{\circ} \mathrm{C}$ until use.

\subsection{Building Library Sequencing}

The sequencing library was prepared using the NEBNext $\left(U\right.$ ltra $^{\mathrm{TM}}$ directed RNA library preparation kit for Illumina $($ (NEB, Ipswich, MA, USA), which enabled the addition of index codes to the sequence. After the RNA samples passed the test, the ribo-zero kit was used to remove the rRNA and enrich the mRNA. On the basis of single - stranded cDNA synthesized with mRNA as the template, the synthesis of double-stranded cDNA was completed. The cDNA fragments were purified using the AMPure XP system (Beckman Coulter, Beverly, MA, USA), the purified double-stranded cDNA was connected to the sequencing joint and the desired fragment size was selected. Finally, PCR amplification was performed to purify the product and construct the final library. Primer Index (X), Phusion high-fidelity DNA polymerase and universal PCR primers were used for the reaction. The Agilent Biological Analyzer 2100 system was used to evaluate the quality of the product and library.

\subsection{Bioinformatic Analysis}

Sequence information and quality were evaluated through the establishment of a library and the original sequencing obtained by high-throughput sequencing. To ensure that analysis requirements were met, low quality spliced raw reads were filtered to obtain high quality clean reads for subsequent sequencing analysis. The most commonly used measure of gene expression level was FPKM, the number of fragments per 1000 base length of a gene per million fragments. FPKM could detect the effects of gene length on reading and depth. Volcanic maps were used to estimate the overall distribution of differential genes. During the GO enrichment analysis, we considered $p<0.05$ as significantly enriched. KEGG is a database that can systematically analyze gene function and genomic information. We used KOBAS software to conduct a holistic study on gene and expression information in the KEGG pathway.

\section{6. qRT-PCR Validation of Differentially Expressed Genes}

To verify transcriptomics results, RNA was purified using the PrimeScript ${ }^{\text {TMRT }}$ kit and gDNA eraser (TaKaRa, Dalian, China), and cDNA synthesis was performed after genomic DNA was removed.

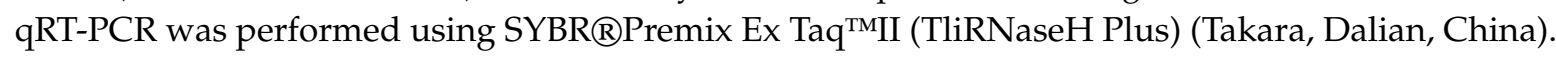
The 16S rRNA gene was selected as the reference gene, and gene expression calculation was performed 
using the $2^{-\Delta \Delta C t}$ method [43]. Primer 5.0 software (PREMIER Biosoft, Palo Alto, CA, USA) was used to design specific primers, as shown in Table 3.

Table 3. Primers used to verify gene expression level by quantitative real-time polymerase chain reaction (qRT-PCR).

\begin{tabular}{|c|c|c|}
\hline Gene & Primer & Sequence $\left(5^{\prime} \rightarrow 3^{\prime}\right)$ \\
\hline \multirow{2}{*}{$16 S$ rRNA } & $16 S$ rRNA-F & GCGGCCCCCTGGACAATGAC \\
\hline & $\begin{array}{c}16 S r \\
R N A-\mathrm{R}\end{array}$ & TAGCTAAGGAAGCCACGCCT \\
\hline \multirow{2}{*}{ ssat } & $s s a T-F$ & ATCGGTCGGCACAACAAC \\
\hline & ssaT-R & GATGAAGAGCATAAGGGA \\
\hline \multirow{2}{*}{ STY2897 } & STY2897-F & ATGGATGGGTGTCGTGTC \\
\hline & STY2897-R & GAATGGTCGCCTTTACTG \\
\hline \multirow{2}{*}{ pagC } & pagC-F & TACGGCTCTTTTATGGTTGGG \\
\hline & pagC-R & ATCCTGAGTGGAATGTTCTTTA \\
\hline \multirow{2}{*}{$y s c R$} & $y s c R-F$ & ATGTCTTTACCCGATTCGCCTTTG \\
\hline & $y s c R-R$ & ACTTGTTGAATACCCAGAGC \\
\hline \multirow{2}{*}{$s s e B$} & sseB-F & GGTGTTTTGCTTATTCTCCTTA \\
\hline & $\operatorname{sse} B-\mathrm{R}$ & CATCCATCTCATTTGACTTTTC \\
\hline \multirow{2}{*}{ sifB } & sifB-F & GCTATGTTGCTTGTTCCCTG \\
\hline & $\operatorname{sif} B-\mathrm{R}$ & СТTTTСТTTССТGTTCСTTC \\
\hline \multirow{2}{*}{ ssaH } & $s s a H-F$ & AACCATAGCCTGATTTCC \\
\hline & ssaH-R & GCCAACAATAATGCCAGA \\
\hline \multirow{2}{*}{$s s e D$} & sseD-F & GCTATGTTGCTTGTTCCCTG \\
\hline & sseD-R & GCGGCTTTTCTTTCCTGTTC \\
\hline
\end{tabular}

\subsection{Inhibition of S. typhimurium Motility}

According to Sheng et al. [44], swimming and swarming media were prepared. After sterilization and cooling, $500 \mu \mathrm{L}$ of BITC reserve solution at different concentrations (MIC, 1/2MIC, 1/4MIC, 1/8MIC) was added and mixed evenly. The reversed plate was cooled and dried, and equal amounts of normal saline were added as a negative control. Bacterial solution $(3 \mu \mathrm{L})$ in the logarithmic growth phase was added to the center, and the diameter of the diffusion circle was measured after being cultured upside down in a constant temperature incubator at $37^{\circ} \mathrm{C}$ for $12 \mathrm{~h}$ and $48 \mathrm{~h}$ to observe the effects of BITC on the swimming and swarming abilities of S. typhimurium, respectively.

\subsection{Scanning Electron Microscopy (SEM)}

According to the previously reported method [45], a cover glass was placed in a 6-well microtitration plate, and S. typhimurium bacteria and certain nutrients were added for overnight coculture. Different concentrations of BITC were added until the final concentrations reached 1/4 MIC and 1/8 MIC. MH was added to the control group. The slides were subsequently rinsed with PBS several times, soaked in $2.5 \%$ glutaraldehyde to fix the biofilms on the slides and then dried with ethanol at concentrations of $50 \%, 70 \%, 80 \%, 90 \%$, and $100 \%$. The finished slides were glued to the table, sprayed with gold and then observed under SEM (JSM6360, JEOL, Tokyo, Japan).

\subsection{Statistical Analysis}

The data were presented as the mean \pm standard deviation $(n=3)$. The difference between the samples were considered statistically significant when $p<0.05$.

\section{Conclusions}

Research on the antibacterial mechanism of BITC against foodborne pathogens is of great significance for food safety. In this study, transcriptome analysis and phenotypic validation were used for the first time to further explore the expression differences of pathogenicity-related genes. 
The other important differentially expressed genes as well as proteomics are needed to further verify the mechanism of bacteriostasis of BITC. These results are helpful for studying the antibacterial mechanisms of natural extracts against $S$. typhimurium.

Author Contributions: G.-L.Z. conceived and designed the project. G.-L.Z. and X.-N.W. drafted the manuscript; X.-N.W. and T.-X.N. performed the experiments; H.-Y.W. and J.-R.B. analyzed data. H.-S.H. and H.-M.H. modified the manuscript. All authors discussed the results and approved the final manuscript.

Funding: This research was funded by The National Key R and D Program of China (No. 2019YFC1605904), and The Liaoning Provincial Natural Science Foundation of China (2019-MS-021).

Conflicts of Interest: The authors declare no conflict of interest.

\section{Abbreviations}

$\begin{array}{ll}\text { BITC } & \text { benzyl isothiocyanate } \\ \text { DEGs } & \text { differential expression genes } \\ \text { FPKMs } & \text { Fragments Per Kilobase of exon model per Million mapped reads } \\ \text { GO } & \text { Gene Ontology } \\ \text { KEGG } & \text { Kyoto Encyclopedia of Genes and Genomes } \\ \text { qRT-PCR } & \text { quantitative Real-time Polymerase Chain Reaction } \\ \text { SEM } & \text { scanning electron microscopy }\end{array}$

\section{References}

1. Franz, C.; Besten, H.M.W.; Böhnlein, C.; Gareis, M.; Zwietering, M.H.; Fusco, V. Microbial food safety in the 21st century: Emerging challenges and foodborne pathogenic bacteria. Trends Food Sci. Tech. 2019, 84, 34-37. [CrossRef]

2. Feasey, N.A.; Dougan, G.; Kingsley, R.A.; Heyderman, R.S.; Gordon, M.A. Invasive non-typhoidal Salmonella disease: An emerging and neglected tropical disease in Africa. Lancet 2012, 379, 2489-2499. [CrossRef]

3. Dhanani, A.S.; Blck, G.; Dewar, K.; Forgetta, V.; Topp, E.; Beiko, R.G. Genomic comparison of nontyphoidal Salmonella enterica serovars Typhimurium, Enteritidis, Heidelberg, Hadar and Kentucky isolates from broiler chickens. PLoS ONE 2015, 10, e0128773.

4. Morgan, E.; Campbell, J.D.; Rowe, S.C.; Bispham, J.; Stevens, M.P.; Bowen, A.J.; Barrow, P.A.; Maskell, D.J.; Wallis, T.S. Identification of host-specific colonization factors of Salmonella enterica serovar Typhimurium. Mol. Microbiol. 2004, 54, 994-1010. [CrossRef] [PubMed]

5. Dean, S.N.; Bishop, B.M.; Hoek, M.L. Susceptibility of Pseudomonas aeruginosa biofilm to alpha-helical peptides: D-enantiomer of LL-37. Front. Microbiol. 2011, 2, 128. [CrossRef]

6. Brown, H.L.; Reuter, M.; Salt, L.J.; Cross, K.L.; Betts, R.P.; Vliet, A.H. Chicken juice enhances surface attachment and biofilm formation of Campylobacter jejuni. Appl. Environ. Microb. 2014, 80, 7053-7060. [CrossRef]

7. Hall, S.; McDermott, C.; Anoopkumar, D.S.; McFarland, A.J.; Forbes, A.; Perkins, A.V.; Davey, A.K.; Chess, W.R.; Kiefel, M.J.; Arora, D. Cellular effects of pyocyanin, a secreted virulence factor of Pseudomonas aeruginosa. Toxins 2016, 9, 236. [CrossRef]

8. Bridier, A.; Sanchez, V.P.; Guilbaud, M.; Piard, J.C.; Naitali, M.; Briandet, R. Biofilm-associated persistence of food-borne pathogens. Food Microbiol. 2015, 2, 167-178. [CrossRef]

9. Sharma, V.K.; Carlson, S.A. Simultaneous detection of Salmonella strains and Escherichia coli O157:H7 with fluorogenic PCR and single enrichment-broth culture. Appl. Environ. Microb. 2000, 66, 5472-5476. [CrossRef]

10. Diao, M.; Qi, D.; Xu, M.; Lu, Z.; Lv, F.; Bie, X.; Zhang, C.; Zhao, H. Antibacterial activity and mechanism of monolauroyl-galactosylglycerol against Bacillus cereus. Food Control. 2018, 85, 339-344. [CrossRef]

11. Romeo, L.; Iori, R.; Rollin, P.; Bramanti, P.; Mazzon, E. Isothiocyanates: An overview of their antimicrobial activity against human infections. Molecules 2018, 23, 624. [CrossRef] [PubMed]

12. Han, K.W.W.; Po, W.W.; Sohn, U.D.; Kim, H.J. Benzyl isothiocyanate induces apoptosis viareactive oxygen species-initiated mitochondrial dysfunction and DR4 and DR5 deathreceptor activation in gastric adenocarcinoma cells. Biomolecules 2019, 9, 839. [CrossRef] [PubMed] 
13. Ranjan, A.; Ramachandran, S.; Gupta, N.; Kaushik, I.; Wright, S.; Srivastava, S.; Das, H.; Srivastava, S.; Prasad, S.; Srivastava, S.K. Role of phytochemicals in cancer prevention. Int. J. Mol. Sci. 2019, $20,4981$. [CrossRef] [PubMed]

14. Soundararajan, P.; Kim, J.S. Anti-carcinogenic glucosinolates in cruciferous vegetables and their antagonistic effects on prevention of cancers. Molecules 2018, 23, 2983. [CrossRef]

15. Borges, A.; Abreu, A.C.; Ferreira, C.; Saavedra, M.J.; Simoes, L.C.; Simoes, M. Antibacterial activity and mode of action of selected glucosinolate hydrolysis products against bacterial pathogens. J. Food Sci. Technol. 2015, 52, 4737-4748. [CrossRef]

16. Kaiser, S.J.; Mutters, N.T.; Blessing, B.; Günther, F. Natural isothiocyanates express antimicrobial activity against developing and mature biofilms of Pseudomonas aeruginosa. Fitoterapia 2017, 119, 57-63. [CrossRef]

17. Saleh, N.M.; Mabrouk, M.I.; Salem-Bekhit, M.M.; Hafez, E.H. Challenge of moringa peregrine forssk as an antimicrobial agent against multi-drug-resistant Salmonella sp. Biotechnol. Biotechnol. Equip. 2017, 31, 380-386. [CrossRef]

18. Cadena, M.; Froenicke, L.; Britton, M.; Settles, M.L.; Durbin-Johnson, B.; Kumimoto, E.; Pitesky, M. Transcriptome analysis of Salmonella Heidelberg after exposure to cetylpyridinium chloride, acidifed calcium hypochlorite, and peroxyacetic acid. J. Food Protect. 2019, 82, 109-119. [CrossRef]

19. Siroli, L.; Braschi, G.; Jong, A.; Kok, J.; Patrignani, F.; Lanciotti, R. Transcriptomic approach and membrane fatty acid analysis to study the response mechanisms of Escherichia coli to thyme essential oil, carvacrol, 2- (E) -hexanal and citral exposure. J. Appl. Microbiol. 2018, 125, 1308-1320. [CrossRef]

20. Li, W.V.; Li, J.J. Modeling and analysis of RNA-seq data: A review from a statistical perspective. Quant. Biol. 2018, 6, 195-209. [CrossRef]

21. Chiricosta, L.; Silvestro, S.; Pizzicannella, J.; Diomede, F.; Bramanti, P.; Trubiani, O.; Mazzon, E. Transcriptomic analysis of stem cells treated with moringin or cannabidiol: Analogies and differences in inflammation pathways. Int. J. Mol. Sci. 2019, 20, 6039. [CrossRef]

22. Das, Q.; Lepp, D.; Yin, X.; Ross, K.; McCallum, J.L.; Warriner, K.; Marcone, M.F.; Diarra, M.S. Transcriptional profiling of Salmonella enterica serovar Enteritidis exposed to ethanolic extract of organic cranberry pomace. PLoS ONE 2019, 14, e0219163. [CrossRef]

23. Huang, X.; Zhou, X.; Jia, B.; Li, N.; Jia, J.; He, M.; He, Y.; Qin, X.; Cui, Y.; Shi, C.; et al. Transcriptional sequencing uncovers survival mechanisms of Salmonella enterica serovar Enteritidis in antibacterial egg white. mSphere 2019, 4, e00700-18. [CrossRef]

24. Song, J.; Hou, H.M.; Wu, H.Y.; Li, K.X.; Wang, Y.; Zhou, Q.Q.; Zhang, G.L. Transcriptomic analysis of Vibrio parahaemolyticus reveals different virulence gene expression in response to benzyl isothiocyanate. Molecules 2019, 24, 761. [CrossRef]

25. Wang, X.N.; Wu, H.Y.; Niu, T.X.; Bi, J.R.; Hou, H.M.; Hao, H.S.; Zhang, G.L. Downregulated expression of virulence factors induced by benzyl isothiocyanate in Staphylococcus aureus: A transcriptomic analysis. Int. J. Mol. Sci. 2019, 20, 5441. [CrossRef]

26. Wafa, B.A.; Makni, M.; Ammar, S.; Khannous, L.; Hassana, A.B.; Bouaziz, M.; Es-Safi, N.E.; Gdoura, R. Antimicrobial effect of the Tunisian Nana variety Punica granatum L. extracts against Salmonella enterica (serovars Kentucky and Enteritidis) isolated from chicken meat and phenolic composition of its peel extract. Int. J. Food Microbiol. 2017, 241, 123-131. [CrossRef]

27. Xiao, X.N.; Wang, F.; Yuan, Y.; Liu, J.; Liu, Y.Z.; Yi, X. Antibacterial activity and mode of action of dihydromyricetin from ampelopsis grossedentata leaves against food-borne bacteria. Molecules 2019, 24, 2831. [CrossRef]

28. Patel, J.; Yin, H.B.; Bauchan, G.; Mowery, J. Inhibition of Escherichia coli O157:H7 and Salmonella enterica virulence factors by benzyl isothiocyanate. Food Microbiol. 2019, 86, 103303. [CrossRef]

29. Cuggino, S.G.; Bascon, V.I.; Rincon, F.; Perez, M.A.; Posada, I.G.; Marugan, J.; Carro, C.P.; Perez, R.F. Modelling the combined effect of chlorine, benzyl isothiocyanate, exposure time and cut size on the reduction of Salmonella in fresh-cut lettuce during washing process. Food Microbiol. 2019, 86, 103346. [CrossRef]

30. Yang, C.X.; Wu, H.T.; Li, X.X.; Wu, H.Y.; Niu, T.X.; Wang, X.N.; Lian, R.; Zhang, G.L.; Hou, H.M. Comparison of the inhibitory potential of benzyl isothiocyanate and phenethyl isothiocyanate on Shiga toxin-producing and enterotoxigenic Escherichia coli. LWT-Food Sci. Technol. 2020, 118, 108806. [CrossRef] 
31. Zhu, A.; Zhi, W.; Qiu, Y.; Wei, L.; Tian, J.; Pan, Z.; Duan, L. Surveillance study of the prevalence and antimicrobial resistance of Salmonella in pork from open markets in Xuzhou, China. Food Control. 2019, 98, 474-480. [CrossRef]

32. Moest, T.P.; Meresse, S. Salmonella T3SSs: Successful mission of the secret (ion) agents. Curr. Opin. Microbiol. 2013, 16, 38-44. [CrossRef] [PubMed]

33. Barrow, P.A.; Freitas, O.C. Pullorum disease and fowl typhoid-new thoughts on old diseases: A review. Avian Pathol. 2011, 40,1-13. [CrossRef]

34. Barletta, F.; Mercado, E.H.; Lluque, A.; Ruiz, J.; Cleary, T.G.; Ochoa, T.J. Multiplex real-time PCR for detection of Campylobacter, Salmonella, and Shigella. J. Clin. Microbiol. 2013, 51, 2822-2829. [CrossRef]

35. Yong, M.; Su, J.D.; Yan, F.; Gang, L.; Hong, J.; Jun, F. Antimicrobial activity of anthocyanins and catechins against foodborne pathogens Escherichia coli and Salmonella. Food Control. 2019, 106, 106712.

36. Anderson, M.T.; Mitchell, L.A.; Sintsova, A.; Rice, K.A.; Mobleya, H.L.T. Sulfur Assimilation Alters Flagellar Function and Modulates the Gene Expression Landscape of Serratia marcescens. Microbiology 2019, 4, e00285-19. [CrossRef]

37. Lou, Z.; Letsididi, K.S.; Yu, F. Inhibitive effect of eugenol and its nanoemulsion on quorum sensing-mediated virulence factors and biofilm formation by Pseudomonas aeruginosa. J. Food Prot. 2019, 82, 379-389.

38. John, K.M.M.; Bhagwat, A.A.; Luthria, D.L. Swarm motility inhibitory and antioxidant activities of pomegranate peel processed under three drying conditions. Food Chem. 2017, 253, 145-153. [CrossRef]

39. Selwan, H.; Wang, X.; Riham, M.S.; Mohamed, E.; Philip, D.A.; Christopher, V. Synergistic action of SPI-1 gene expression in Salmonella enterica serovar typhimurium through transcriptional crosstalk with the flagellar system. BMC Microbiol. 2019, 19, 211.

40. Smriti, V.; Rachel, A.P.; Laura, I.; Kourtney, P.N.; Emily, H.; Christina, S.F.; Alessio, F.; Stefania, S.; Bobby, J.C. The YrbE phospholipid transporter of Salmonella enterica serovar Typhi regulates the expression of flagellin and influences motility, adhesion and induction of epithelial inflammatory responses. Gut Microbes. 2019, 1949, 0976-0984.

41. Hu, W.S.; Nam, D.M.; Choi, J.Y.; Kim, J.S.; Koo, O.K. Anti-attachment, anti-biofilm, and antioxidant properties of Brassicaceae extracts on Escherichia coli O157:H7. Food Sci. Biotechnol. 2019, 28, 1881-1890. [CrossRef] [PubMed]

42. Khan, M.; Alkhathlan, H.Z.; Khan, S.T. Antibiotic and antibiofilm activities of Salvadora persica L. essential oils against Streptococcus mutans: A detailed comparative study with chlorhexidine digluconate. Pathogens 2020, 9, 66. [CrossRef] [PubMed]

43. Livak, K.J.; Schmittgen, T.D. Analysis of relative gene expression data using real-time quantitative PCR andthe 2 (-Delta Delta C (T)) method. Methods 2001, 25, 402-408. [CrossRef] [PubMed]

44. Sheng, J.Y.; Chen, T.T.; Tan, X.J.; Chen, T.; Jia, A.Q. The quorum-sensing inhibiting effects of stilbenoids and their potential structure-activity relationship. Bioorg. Med. Chem. Lett. 2015, 25, 5217-5220. [CrossRef]

45. Suo, B.; Li, H.; Wang, Y.; Li, Z.; Pan, Z.; Ai, Z. Effects of ZnO nanoparticle-coated packaging film on pork meat quality during cold storage. J. Sci. Food Agric. 2017, 97, 2023-2029. [CrossRef] [PubMed]

(C) 2020 by the authors. Licensee MDPI, Basel, Switzerland. This article is an open access article distributed under the terms and conditions of the Creative Commons Attribution (CC BY) license (http://creativecommons.org/licenses/by/4.0/). 